\title{
Oxidative damage mediates the association between polycyclic aromatic hydrocarbon exposure and lung function
}

Limin Cao ${ }^{1,2}$, Yun Zhou ${ }^{1,2}$, Aijun Tan ${ }^{3}$, Tingming Shi ${ }^{4}$, Chunmei Zhu ${ }^{1,2}$, Lili Xiao ${ }^{1,2}$, Zhuang Zhang ${ }^{1,2}$, Shijie Yang ${ }^{1,2}$, Ge Mu ${ }^{1,2}$, Xing Wang ${ }^{1,2}$, Dongming Wang ${ }^{1,2}$, Jixuan $\mathrm{Ma}^{1,2+}$ and Weihong Chen ${ }^{1,2^{*}+}$ (D)

\begin{abstract}
Background: Exposure to polycyclic aromatic hydrocarbons (PAHs) is related to decreased lung function. However, whether oxidative damage is involved in this relationship remains unclear. This study was aimed to explore the potential mediating role of oxidative DNA or lipid damage in the association between PAH exposure and lung function.

Methods: The urinary levels of monohydroxy polycyclic aromatic hydrocarbon metabolites (OH-PAHs) and lung function parameters were measured among 3367 participants from the baseline of the Wuhan-Zhuhai cohort. Urinary 8-hydroxy2'-deoxyguanosine (8-OHdG) and 8-isoprostane (8-iso-PGF2a) were determined to evaluate the individuals' oxidative DNA and lipid damage degrees, respectively. Linear mixed models were used to investigate the associations of urinary $\mathrm{OH}$ PAHs, 8-OHdG and 8-iso-PGF2a with lung function parameters. Mediation analysis was further conducted to assess the potential role of oxidative damage in the association between urinary $\mathrm{OH}-\mathrm{PAHs}$ and lung function.
\end{abstract}

Results: Each one-percentage increase in the sum of urinary OH-PAHs, high-molecular-weight or low-molecular-weight OH-PAHs ( $\Sigma \mathrm{OH}-\mathrm{PAHS}$, $\Sigma$ HMW OH-PAH or $\Sigma \mathrm{LMW}$ OH-PAHs, respectively) was associated with a 0.2152-, 0.2076- or 0.1985$\mathrm{ml}$ decrease in $\mathrm{FEV}_{1}$, and a $0.1891-, 0.2195$ - or $0.1634-\mathrm{ml}$ decrease in $\mathrm{FVC}$, respectively. Additionally, significantly positive dose-response relationships of $\Sigma \mathrm{OH}-\mathrm{PAHs}$, $\mathrm{HHMW} \mathrm{OH}-\mathrm{PAH}$ and $\Sigma \mathrm{LMW} \mathrm{OH}-\mathrm{PAHs}$ with urinary 8-OHdG or 8-iso-PGF2a, as well as an inverse dose-response relationship between urinary 8-OHdG and FVC, were observed (all $P$ for trend $<0.05$ ). Mediation analysis indicated that urinary $8-\mathrm{OHdG}$ mediated $14.22 \%$ of the association between $\mathrm{HHMW}$ OH-PAH and FVC.

Conclusion: Higher levels of oxidative DNA damage might be involved in the decreased levels of FVC caused by highmolecular-weight PAH exposure.

Keywords: Polycyclic aromatic hydrocarbons, Oxidative damage, Lung function, Mediation effect

\footnotetext{
* Correspondence: wchen@mails.tjmu.edu.cn

${ }^{\dagger}$ Jixuan Ma and Weihong Chen contributed equally to this work.

'Department of Occupational \& Environmental Health, School of Public

Health, Tongji Medical College, Huazhong University of Science and

Technology, Wuhan 430030, Hubei, China

${ }^{2}$ Key Laboratory of Environment and Health, Ministry of Education \& Ministry

of Environmental Protection, and State Key Laboratory of Environmental

Health (Incubating), School of Public Health, Tongji Medical College,

Huazhong University of Science and Technology, Wuhan 430030, Hubei,

China

Full list of author information is available at the end of the article
}

(c) The Author(s). 2020 Open Access This article is licensed under a Creative Commons Attribution 4.0 International License, which permits use, sharing, adaptation, distribution and reproduction in any medium or format, as long as you give appropriate credit to the original author(s) and the source, provide a link to the Creative Commons licence, and indicate if changes were made. The images or other third party material in this article are included in the article's Creative Commons licence, unless indicated otherwise in a credit line to the material. If material is not included in the article's Creative Commons licence and your intended use is not permitted by statutory regulation or exceeds the permitted use, you will need to obtain permission directly from the copyright holder. To view a copy of this licence, visit http://creativecommons.org/licenses/by/4.0/ The Creative Commons Public Domain Dedication waiver (http://creativecommons.org/publicdomain/zero/1.0/) applies to the data made available in this article, unless otherwise stated in a credit line to the data. 


\section{Background}

Polycyclic aromatic hydrocarbons (PAHs) are a group of widespread environmental pollutants, primarily derived from incomplete combustion of fossil fuels and biomass [1]. Compared with natural exposure sources, industrial production processes, motor vehicle exhaust, cigarette smoking and residential fuel combustion are the main emission sources of PAHs in the human living environment [2]. In recent years, exposure to PAHs has been demonstrated to be associated with adverse health effects on various organs [3-7], especially the respiratory system $[8,9]$. As an early indicator of respiratory damage, lung function can be used to predict the long-term morbidity and mortality of several diseases including nonrespiratory diseases $[10,11]$. Additionally, a recent study of our research group has already discovered a significant association between urinary monohydroxy polycyclic aromatic hydrocarbons (OH-PAHs) and decreased lung function [8]. However, the underlying mechanisms remain incompletely understood.

Oxidative stress is an imbalance between oxidant and antioxidant capacity due to the overproduction of oxidative products [12] and is commonly considered to be involved in the pathogenesis of adverse health effects induced by PAH exposure [13, 14]. Accumulated oxidative products could initiate oxidative damage by attacking biological macromolecules in tissues, such as proteins, lipids and DNA [15]. Urinary 8-hydroxy-2'deoxyguanosine (8-OHdG), one of the predominant forms of oxidative DNA lesions, is widely used as a biomarker for oxidative DNA damage in large-sample population studies $[16,17]$. Similarly, urinary 8isoprostane (8-iso-PGF2 $\alpha$ ), the terminal product of cell membrane lipidperoxidation with strong chemical stability, could reflect oxidative damage of lipids $[18,19]$. Both epidemiology and toxicology studies have observed elevated levels of oxidative damage along with $\mathrm{PAH}$ exposure [12, 18, 20].

Although elevated levels of oxidative damage were reported in various airway diseases, such as asthma [21, 22], bronchiectasis [23], chronic obstructive pulmonary disease (COPD) [24-26] and idiopathic pulmonary fibrosis [27, 28], the relationship between oxidative damage and lung function alteration in healthy adults has been scarcely reported. Moreover, whether oxidative damage plays a potential role in lung function decline induced by PAH exposure remains largely unknown.

Thus, it is reasonable to assume that increased oxidative damage level may mediate the relationship between $\mathrm{PAH}$ exposure and lung function. In the present study, we determined urinary $\mathrm{OH}-\mathrm{PAHs}$ as biomarkers for $\mathrm{PAH}$ exposure, measured urinary 8-OHdG and 8-isoPGF $2 \alpha$ levels as oxidative damage biomarkers and conducted lung function tests in 3367 participants from the baseline of the Wuhan-Zhuhai cohort. The associations of PAH exposure with lung function parameters and oxidative damage levels were assessed by using linear mixed models and restricted cubic spline regression models. Furthermore, mediation analysis was conducted to explore the role of oxidative damage biomarkers in the associations of lung function with $\mathrm{PAH}$ exposure.

\section{Methods}

\section{Study population}

This study was based on the Wuhan-Zhuhai (WHZH) cohort, which was described previously [29]. Briefly, 4812 adults dwelling in Wuhan or Zhuhai for more than 5 years were recruited. Before the physical examination, all the participants were informed to keep fasting for more than $12 \mathrm{~h}$. During the investigation, they were required to complete the physical examinations and structured questionnaires and provide early-morning urine samples. The urine samples were collected in polypropylene containers and frozen until analysis. Detailed information on the demographic characteristics and lifestyle was obtained from questionnaires by face-toface interviews. It included age, gender, education level, annual family income, ever occupational hazard exposure, smoking status, smoking amounts, passive smoking status, drinking status, cooking status, regular physical activity, sleep duration at night, diet information (including self-reported frequencies of food intake) and selfreported history of diseases.

In the current study, education levels were classified into three groups: low (middle school and below), middle (high school) and high (university or above). Annual family income was divided into three levels: $<30,000,30$, $000-70,000$ and $\geq 70,000$ Yuan. Individuals who drank once a week for at least 6 months were defined as current drinkers and those who smoked at least one cigarette per day for more than 6 months were defined as current smokers. Smoking amounts (pack-years) for smokers were further calculated as packs of cigarettes per day multiplied by years of smoking. Passive smoking was defined as passive exposure to tobacco smoke for more than 1 day per week anywhere. Regular exercise within the last 6 months was considered as active physical activity. Self-reported respiratory diseases were defined as having at least one disease, including COPD, asthma, emphysema, chronic bronchitis, pneumoconiosis and pleurisy. Additionally, physical examinations were conducted by trained physicians. Body mass index (BMI) was calculated as weight $(\mathrm{kg})$ divided by height $(\mathrm{m})$ squared.

Excluding participants with self-reported respiratory diseases $(N=253)$ and potential occupational PAH exposure $(N=33)$, or with missing data on lung function index $(N=55)$, urinary OH-PAHs $(N=652), 8$-OHdG 
$(N=344)$ and 8-iso-PGF2 $\alpha(N=56)$ as well as with missing data on life habits, such as sleep duration and diet information $(N=52), 3367$ participants were included in the final analysis. The research protocol was approved by the Ethics and Human Subjects Committee of Tongji Medical College, Huazhong University of Science and Technology. Likewise, everyone signed written informed consent.

\section{Determination of urinary OH-PAHs}

Twelve urinary $\mathrm{OH}-\mathrm{PAHs}$, including 1-hydroxypyrene (1-OHP), 6-hydroxychrysene (6-OHChr), 3-hydroxybenzo[a]pyrene (3-OHBaP), 1-hydroxynaphthalene (1-OHNa), 2-hydroxynaphthalene (2-OHNa), 2-hydroxyfluorene (2OHFlu), 9-hydroxyfluorene (9-OHFlu), 1-hydroxyphenanthrene (1-OHPh), 2-hydroxyphenanthrene (2-OHPh), 3hydroxyphenanthrene (3-OHPh), 4-hydroxyphenanthrene (4-OHPh) and 9-hydroxyphenanthrene (9-OHPh) were determined by gas chromatography-mass spectrometry (GC/MS; Agilent $6890 \mathrm{~N}+59758 \mathrm{~B}$, Agilent Technologies Inc., Santa Clara, CA, USA) as previously reported by Li et al. [30]. Ten percent of urine samples were measured in duplicate for repeatability tests, and the coefficient of variation in the duplicate analysis was below $10 \%$. Because the concentrations of $6-\mathrm{OHChr}$ and $3-\mathrm{OHBaP}$ were mostly below the limits of detection (LOD), the other $10 \mathrm{PAH}$ metabolites remained in the final analysis. The LOD for urinary PAH metabolites ranged from 0.1 to $0.9 \mu \mathrm{g} / \mathrm{l}$, and concentrations below the LOD were replaced by half the value of the LOD. Valid concentrations of OH-PAHs were calibrated by the levels of urinary creatinine (creat.) and expressed as $\mu \mathrm{mol} / \mathrm{mol}$ creat, due to the urine dilution. For analysis, the sum of all OH-PAHs ( $(\mathrm{OH}-\mathrm{PAHs})$ and sum of high- ( $\geq 4$ rings, including $1-\mathrm{OHP})$ or low- $(<4$ rings, including 1-OHNa, 2-OHNa, 2-OHFlu, 9-OHFlu, 1-OHPh, 2-OHPh, 3-OHPh, 4-OHPh and 9-OHPh) molecularweight $\mathrm{OH}-\mathrm{PAHs}$ ( $\mathrm{H} \mathrm{HMW} \mathrm{OH}-\mathrm{PAH}$ or $\Sigma \mathrm{LMW} \mathrm{OH}-$ PAHs) were used in this study.

\section{Determination of urinary 8-OHdG}

The urinary levels of 8 -OHdG were measured using high-performance liquid chromatography (HPLC) coupled with an electrochemical detector (Waters 2645; Waters Inc., USA). The cleanup and analysis processes were performed as described previously [31]. The coefficient of variation was less than $5 \%$ in duplicate analysis, and the recoveries of spiked samples ranged from 75 to $120 \%$. Similarly, the concentrations below the LOD were replaced by half of the LOD. Valid concentrations of 8OHdG were calculated as $\mu \mathrm{mol} / \mathrm{mol}$ creat.

\section{Determination of urinary 8-iso-PGF2a}

The urinary concentrations of 8-iso-PGF2 $\alpha$ were determined using a commercially available ELISA kit
(Cayman, USA) following the manufacturer's instructions (Catalog No. 516351). The LOD was approximately $2.7 \mathrm{pg} / \mathrm{ml}$, and the levels of 8-iso-PGF2 $\alpha$ were calibrated by urinary creat. and expressed as $\mathrm{nmol} / \mathrm{mol}$ creat.

\section{Lung function test}

Lung function parameters, including forced expiratory volume in $1 \mathrm{~s}\left(\mathrm{FEV}_{1}\right)$, forced vital capacity $(\mathrm{FVC})$ and the ratio of $\mathrm{FEV}_{1}$ to $\mathrm{FVC}\left(\mathrm{FEV}_{1} \%\right)$, were conducted by specialists using electronic spirometers (Chest graph HI101; CHEST Ltd., Tokyo, Japan), according to the American Thoracic Society Recommendations, as described elsewhere [8]. All participants were informed to maintain normal breathing for at least $5 \mathrm{~min}$ in a sitting position with a nose clip in place before the test. Meanwhile, participants were advised not to smoke for at least $1 \mathrm{~h}$ and keep fasting for more than $2 \mathrm{~h}$ before the test. The greatest values for $\mathrm{FEV}_{1}, \mathrm{FVC}$ and $\mathrm{FEV}_{1} \%$ were obtained from multiple repeat measurements.

\section{Statistical analysis}

The distributions of the basic characteristics were analyzed according to quartiles of urinary $\Sigma \mathrm{OH}-\mathrm{PAHs}$. Due to the right-skewed distributions and nonnormality of the residuals, the concentrations of urinary $\mathrm{OH}-\mathrm{PAHs}$, 8-OHdG and 8-iso-PGF2 $\alpha$ were natural log-transformed before statistical analysis. Both continuous and categorical variable models were conducted to quantify the associations of urinary $\mathrm{OH}-\mathrm{PAHs}$ with oxidative damage biomarkers (8-OHdG and 8-iso-PGF2 $\alpha$ ) and lung function parameters by linear mixed models and restricted cubic spline regression models. All models were adjusted for age (continuous variable), gender (male/female), height (continuous variable), weight (continuous variable), smoking amounts (continuous variable), passive smoking status (yes/no), drinking status (yes/no), education level (categorical variable), annual family income (categorical variable), regular physical activity (yes/no), cooking meals at home (yes/no), sleep duration at night (continuous variable), eating smoked food $(<1 / \geq 1$ time/ week), eating vegetables or fruits $(<1 / \geq 1$ time/day), eating aquatic products $(<1 / \geq 1$ time/day) and city (Wuhan/ Zhuhai). Stratified analyses were also conducted both in nonsmokers and smokers to ascertain the above associations.

Additionally, mediation analysis was performed to assess the mediating role of oxidative damage biomarkers in the associations between urinary OH-PAHs and lung function. We used linear mixed models to explore the associations of exposure-outcome (OH-PAHs and lung function), exposure-mediator (OH-PAHs and oxidative damage biomarkers) and exposure-mediator-outcome (OH-PAHs, oxidative damage biomarkers and lung function) (Eqs (1) to (3)), respectively. 


$$
\begin{aligned}
\mathrm{Y}= & \alpha_{0}+\phi_{0}+\alpha_{1} X_{1}+\alpha_{2} X_{2}+\cdots \\
& +\alpha_{O H-P A H S} X_{O H-P A H s}+\omega \\
\mathrm{M}= & \beta_{0}+\varepsilon_{0}+\beta_{1} X_{1}+\beta_{2} X_{2}+\cdots \\
& +\beta_{O H-P A H s} X_{O H-P A H s}+\mu \\
Y^{\prime}= & \gamma_{0}+\delta_{0}+\gamma_{1} X_{1}+\gamma_{2} X_{2}+\cdots \\
& +\gamma_{O H-P A H s} X_{O H-\mathrm{PAHs}}+\gamma_{M} M+\rho
\end{aligned}
$$

In each equation, $\mathrm{X}=$ independent variable (including $\mathrm{OH}-\mathrm{PAHs}$ and covariates), $\mathrm{M}=$ mediator (oxidative damage biomarkers), and $\mathrm{Y}\left(\right.$ or $\left.\mathrm{Y}^{\prime}\right)=$ dependent variable (lung function parameters). $\alpha_{O H-P A H s}$ presents the total effect, $\gamma_{O H-P A H s}$ presents the direct effect, and the mediated effect is calculated as the product of $\beta_{O H-P A H s}$ and $\gamma_{M}$.

We also performed a mediation test to calculate confidence limits for the mediated effects of oxidative damage using the PROCESS SPSS macro [32]. Additionally, the proportion mediated is calculated as the ratio of the mediation effect to the total effect. All analyses were performed using SAS version 9.4 (SAS institute, Cary, NC, USA) and SPSS version 17.0 (SPSS Inc., Chicago, IL, USA).

\section{Results}

The basic characteristics of the participants by quartiles of urinary $\mathrm{\Sigma OH}-\mathrm{PAHs}$ are shown in Table 1 . In the present study, the mean age of all 3367 participants was 52.0 years, and one-third were males (31.0\%). The participants with higher levels of urinary $\Sigma \mathrm{OH}-\mathrm{PAHs}$ were more likely to be females, older and to engage in regular physical activity, cook meals or eat smoked food and were less likely to be smokers, drinkers and to have a higher BMI; however, the smoking amounts of smokers were significantly elevated with higher quartiles of urinary $\Sigma \mathrm{OH}-\mathrm{PAHs}$. Moreover, as the concentrations of urinary $\Sigma \mathrm{OH}-\mathrm{PAHs}$ increased, the average values of $\mathrm{FEV}_{1}$ and $\mathrm{FVC}$ were monotonically decreased; whereas the levels of 8-OHdG and 8-iso-PGF2 $\alpha$ were significantly increased.

As displayed in Table 2, each one-percentage increase in urinary $\Sigma \mathrm{OH}-\mathrm{PAHs}$, $\Sigma \mathrm{HMW} \mathrm{OH}-\mathrm{PAH}$ or $\Sigma \mathrm{LMW} \mathrm{OH}-$ PAHs generated a 0.2152-, 0.2076- or 0.1985- ml decrease in $\mathrm{FEV}_{1}$, respectively (all $P<0.01$ ). Only each onepercentage increase in $\Sigma \mathrm{HMW} \mathrm{OH}-\mathrm{PAH}$ was found to be significantly associated with a $-0.2159 \mathrm{ml}$ change in FVC. We also found a marginal association of FVC with $\Sigma \mathrm{OH}$ PAHs or $\Sigma \mathrm{LMW}$ OH-PAHs. In the categorical variable models, $\mathrm{FEV}_{1}$ was monotonically decreased with elevated quartiles of urinary $\Sigma \mathrm{OH}-\mathrm{PAHs}$, $\Sigma \mathrm{HMW} \mathrm{OH}-\mathrm{PAH}$ or $\Sigma$ LMW OH-PAHs (all $P$ for trend $<0.05$ ). A similar trend was observed for FVC with $\Sigma \mathrm{HMW} \mathrm{OH}-\mathrm{PAH}$. Additionally, no significant relationship was observed between urinary OH-PAHs (including $\Sigma \mathrm{OH}-\mathrm{PAHs}$, $\Sigma \mathrm{HMW} \mathrm{OH}-$ $\mathrm{PAH}$ and $\Sigma \mathrm{LMW} \mathrm{OH}-\mathrm{PAHs}$ ) and $\mathrm{FEV}_{1} \%$ (all $P>0.05$ ).
Figure 1 presents the associations of urinary $\mathrm{OH}$ PAHs with 8-OHdG and 8-iso-PGF2 $\alpha$. We observed that significant monotonically elevated levels of $8-\mathrm{OHdG}$ or 8-iso-PGF2 $\alpha$, as the levels of urinary $\Sigma \mathrm{OH}-\mathrm{PAHs}$, $\Sigma \mathrm{HMW} \mathrm{OH}-\mathrm{PAH}$ and $\Sigma \mathrm{LMW} \mathrm{OH}-\mathrm{PAHs}$ increased. Additionally, a nonlinear relationship was revealed between urinary 8-iso-PGF $2 \alpha$ and urinary $\Sigma \mathrm{OH}-\mathrm{PAHs}$ or ELMW OH-PAHs $(P<0.0001)$. Considering that cigarette smoke could induce oxidative damage in humans, stratified analyses by smoking status were further conducted to avoid its interference. The associations between urinary OH-PAHs and 8-OHdG or 8-isoPGF2 $\alpha$ in both nonsmokers and smokers were similar to those of the whole population (data not shown).

The associations between oxidative damage biomarkers and lung function are revealed in Table 3. In continuous variable analysis, each one-percentage increase in urinary 8-OHdG was significantly associated with a $0.1748 \mathrm{ml}$ decrease in FVC. The categorical variable model only showed a significantly negative dose-response relationship of urinary 8 -OHdG with FVC ( $P$ for trend $=0.0430$ ). No significant association was found between urinary 8-isoPGF $2 \alpha$ and any of these lung function parameters.

Table 4 shows the associations between urinary $\mathrm{OH}$ PAHs regarding lung function parameters and the mediation assessment of urinary 8-OHdG among the relationships. It showed that significant mediated effect of 8OHdG in the models associating $\Sigma$ HMW OH-PAH with FVC. The direct effect of urinary $\Sigma \mathrm{HMW} \mathrm{OH}-\mathrm{PAH}$ on FVC was $-18.30 \mathrm{ml}(-39.07 \mathrm{ml}, 2.47 \mathrm{ml})$. Additionally, the mediated proportion by 8 -OHdG in the relationship between LHMW OH-PAH and FVC was $14.22 \%$. However, no significant mediation effect of 8-OHdG was observed regarding the relationships between $\mathrm{PAH}$ exposures and $\mathrm{FEV}_{1}$, as well as between $\mathrm{LLMW}$ OH-PAHs and FVC.

\section{Discussion}

In this study, we found that urinary OH-PAHs were significantly negatively associated with lung function, and positively related to oxidative damage in DNA or lipids. Additionally, inverse dose-response relationships were further observed between urinary 8-OHdG and FVC, indicating that higher 8-OHdG levels might be a risk factor for decreased lung function. Moreover, our results suggest that urinary 8-OHdG may partially mediate the association between urinary $\mathrm{SHMW} \mathrm{OH}-\mathrm{PAH}$ and FVC.

Along with our previous study [8], the associations between $\mathrm{PAH}$ exposure and altered lung function have been widely conducted in occupational [33], pediatric $[34,35]$ and general populations [36]. It is generally believed that oxidative stress plays a pivotal role in the pathogenic process following $\mathrm{PAH}$ exposure. Consistent with our findings, epidemiological studies have observed significant dose-response relationships between urinary 
Table 1 Characteristics of participants by quartiles of urinary $\mathrm{OH}-\mathrm{PAH}$ levels $(\mathrm{N}=3367)$

\begin{tabular}{|c|c|c|c|c|c|}
\hline \multirow[t]{2}{*}{ Characteristics } & \multirow[t]{2}{*}{ All participants } & \multicolumn{4}{|c|}{ Quartiles of $\Sigma \mathrm{OH}-\mathrm{PAHs}, \mu \mathrm{mol} / \mathrm{mol}$ creat. } \\
\hline & & $\begin{array}{l}\text { Quartile } 1 \\
(<24.63)\end{array}$ & $\begin{array}{l}\text { Quartile 2 } \\
(24.63-36.12)\end{array}$ & $\begin{array}{l}\text { Quartile } 3 \\
(36.12-54.86)\end{array}$ & $\begin{array}{l}\text { Quartile } 4 \\
(\geq 54.86)\end{array}$ \\
\hline No. participants & 3367 & 842 & 842 & 842 & 841 \\
\hline Age (years, means $\pm S D$ ) & $52.0 \pm 12.9$ & $49.9 \pm 13.2$ & $51.1 \pm 12.8$ & $53.0 \pm 12.4$ & $53.9 \pm 12.8$ \\
\hline Gender (male, N, \%) & $1042(31.0)$ & $336(39.9)$ & $285(33.9)$ & $241(28.6)$ & $180(21.4)$ \\
\hline Height (cm, means $\pm S D)$ & $159.0 \pm 7.7$ & $160.6 \pm 8.0$ & $159.3 \pm 7.3$ & $158.7 \pm 7.5$ & $157.6 \pm 7.7$ \\
\hline Weight (kg, means $\pm S D)$ & $60.8 \pm 10.5$ & $62.5 \pm 11.0$ & $61.0 \pm 10.8$ & $60.7 \pm 9.9$ & $58.8 \pm 9.8$ \\
\hline BMI $\left(\mathrm{kg} / \mathrm{m}^{2}\right.$, means $\left.\pm \mathrm{SD}\right)$ & $24.0 \pm 3.4$ & $24.2 \pm 3.5$ & $24.0 \pm 3.5$ & $24.1 \pm 3.3$ & $23.7 \pm 3.5$ \\
\hline \multicolumn{6}{|l|}{ Education level $(\mathrm{N}, \%)$} \\
\hline Low & $828(24.6)$ & $190(22.6)$ & $204(24.2)$ & $236(28.0)$ & $198(23.5)$ \\
\hline Middle & $2122(63.0)$ & $540(64.1)$ & $539(64.0)$ & $514(61.1)$ & $529(62.9)$ \\
\hline High & $417(12.4)$ & $112(13.3)$ & $99(11.8)$ & $92(10.9)$ & $114(13.6)$ \\
\hline \multicolumn{6}{|l|}{ Annual family income (Yuan, N, \%) } \\
\hline$<30,000$ & $1924(57.1)$ & $458(54.4)$ & $492(58.4)$ & $497(59.0)$ & $477(56.7)$ \\
\hline $30,000-70,000$ & $1091(32.4)$ & $270(32.1)$ & $277(32.9)$ & $272(32.3)$ & $272(32.3)$ \\
\hline$\geq 70,000$ & $352(10.5)$ & $114(13.5)$ & $73(8.7)$ & $73(8.7)$ & $92(10.9)$ \\
\hline Smokers $^{a}(\mathrm{~N}, \%)$ & $740(21.6)$ & $196(23.3)$ & $193(22.9)$ & $189(22.5)$ & $147(17.5)$ \\
\hline $\begin{array}{l}\text { Smoking amounts }{ }^{\mathrm{b}} \text {, pack-year } \\
\text { (means } \pm \mathrm{SD} \text { ) }\end{array}$ & $24.7 \pm 21.3$ & $20.1 \pm 21.1$ & $24.7 \pm 19.5$ & $27.9 \pm 22.2$ & $26.9 \pm 21.8$ \\
\hline Passive smokers (yes, N, \%) & $1451(43.1)$ & $346(42.4)$ & $357(42.4)$ & $399(47.5)$ & $349(41.5)$ \\
\hline Cook meals (yes, N, \%) & $2500(74.3)$ & $577(68.5)$ & $617(73.3)$ & $644(76.5)$ & $662(78.7)$ \\
\hline Drinking status (yes, N, \%) & $577(17.1)$ & $149(17.7)$ & $169(20.1)$ & $147(17.5)$ & $112(13.3)$ \\
\hline Regular physical activity (yes, N, \%) & $1579(46.9)$ & $393(46.7)$ & $373(44.3)$ & $386(45.8)$ & $427(50.8)$ \\
\hline Sleep duration at night (hours, means \pm SD) & $8.0 \pm 1.4$ & $8.0 \pm 1.7$ & $8.0 \pm 1.3$ & $8.1 \pm 1.4$ & $7.9 \pm 1.3$ \\
\hline Eating smoked food ( $\geq 1$ time/week, $\mathrm{N}, \%$ ) & $1009(30.0)$ & $213(25.3)$ & $250(29.7)$ & $280(33.3)$ & $266(31.6)$ \\
\hline $\begin{array}{l}\text { Eating vegetables or fruits ( } \geq 1 \text { time/day, } \\
\mathrm{N}, \%)\end{array}$ & $3163(93.9)$ & $802(95.3)$ & $791(93.9)$ & $785(93.2)$ & $785(93.3)$ \\
\hline $\begin{array}{l}\text { Eating aquatic products ( } \geq 1 \text { time/day, } \\
N, \%)\end{array}$ & $1128(33.5)$ & $294(34.9)$ & $294(34.9)$ & $277(32.9)$ & $263(31.3)$ \\
\hline $\mathrm{FEV}_{1}(\mathrm{ml}$, means $\pm \mathrm{SD})$ & $2189.4 \pm 586.1$ & $2327.7 \pm 625.5$ & $2215.6 \pm 582.0$ & $2160.3 \pm 547.8$ & $2053.9 \pm 553.1$ \\
\hline FVC (ml, means \pm SD) & $2508.8 \pm 682.5$ & $2640.3 \pm 730.7$ & $2535.7 \pm 675.2$ & $2497.0 \pm 645.0$ & $2358.6 \pm 646.8$ \\
\hline $\mathrm{FEV}_{1} \%$ (means $\pm \mathrm{SD}$ ) & $87.7 \pm 8.4$ & $88.7 \pm 8.0$ & $87.8 \pm 8.0$ & $87.0 \pm 8.6$ & $87.5 \pm 8.9$ \\
\hline 8-OHdG ( $\mu \mathrm{mol} / \mathrm{mol}$ creat., median, IQR) & $62.2(28.0-123.7)$ & $48.0(21.9-90.6)$ & $60.6(26.9-114.0)$ & $66.0(727.9-129.8)$ & $84.4(41.1-179.3)$ \\
\hline $\begin{array}{l}\text { 8-iso-PGF2a (nmol/mol creat., } \\
\text { median, IQR) }\end{array}$ & $177.0(108.9-311.7)$ & $126.3(81.3-195.0)$ & $167.0(104.1-276.4)$ & $207.9(129.9-348.1)$ & $240.8(139.4-504.6)$ \\
\hline
\end{tabular}

Abbreviations: $\mathrm{SOH}$-PAHs Sum of urinary monohydroxy polycyclic aromatic hydrocarbons, 8-iso-PGF2a 8-isoprostane, 8-OHdG 8-hydroxy-2'-deoxyguanosine, BMI Body mass index, FEV 1 Forced expiratory volume in $1 \mathrm{~s}$, FVC Forced vital capacity, FEV $\%$ The ratio of FEV ${ }_{1}$ to FVC, IQR Interquartile range, SD Standard deviation ${ }^{\text {a }}$ Smokers included current and former smokers

${ }^{\mathrm{b}}$ Smoking amounts were calculated as packs of cigarettes per day multiplied by years of smoking

OH-PAHs and oxidative damage in occupational $[18,37]$ and general populations [12]. To avoid possible interference from smoking, which is a strong oxidant [38, 39], we further evaluated such relationships in both smokers and nonsmokers and obtained similar results. Our findings suggest that $\mathrm{PAH}$ exposure is significantly associated with oxidative damage, regardless of cigarette smoking.

Meanwhile, the effects of PAH exposure on oxidative stress were also reported in studies performed in vivo and in vitro $[13,14]$. After being absorbed in the body, PAHs from various sources can be metabolized into active semiquinones via cytochrome P450 enzymes; the free radical intermediates could further generate reactive oxygen species (ROS). Exaggerated activation of ROS could cause oxidative modification of DNA and lipids in lung tissue $[15,40]$, further contributing to lung function reduction.

Furthermore, higher levels of oxidative damage were reported in various respiratory diseases, but few studies 
Table 2 Associations between urinary $\mathrm{OH}-\mathrm{PAHs}$ and lung function parameters $(\mathrm{N}=3367)$

\begin{tabular}{|c|c|c|c|c|c|c|c|}
\hline \multirow{2}{*}{$\begin{array}{l}\text { Urinary } \mathrm{OH}_{-} \\
\text {PAHs }\end{array}$} & \multirow{2}{*}{$\begin{array}{l}\text { Lung } \\
\text { function } \\
\text { parameters }\end{array}$} & \multirow{2}{*}{$\begin{array}{l}\text { Estimated } \\
\text { changes ( } 95 \% \mathrm{Cl} \text { ) } \\
\text { by continuous } \\
\text { OH-PAHs }\end{array}$} & \multicolumn{4}{|c|}{ Estimated changes in $\mathrm{ml}(95 \% \mathrm{Cl})$ by quartile of $\mathrm{OH}-\mathrm{PAHs}$} & \multirow{2}{*}{$\begin{array}{l}P \text { value } \\
\text { for trend }\end{array}$} \\
\hline & & & Quartile 1 & Quartile 2 & Quartile 3 & Quartile 4 & \\
\hline \multirow[t]{4}{*}{$\Sigma \mathrm{OH}-\mathrm{PAHS}$} & & & $<24.63$ & $24.63-36.12$ & $36.12-54.86$ & $\geq 54.86$ & \\
\hline & $\mathrm{FEV}_{1}$ & $-21.52(-40.46,-2.58)$ & 0 (referent) & $-39.63(-76.83,-2.43)$ & $-11.74(-49.41,25.94)$ & $-65.59(-103.42,-27.77)$ & 0.0057 \\
\hline & FVC & $-18.91(-41.95,4.14)$ & 0 (referent) & $-34.69(-79.99,10.61)$ & $2.51(-43.39,48.42)$ & $-57.89(-103.95,-11.83)$ & 0.0651 \\
\hline & $\mathrm{FEV}_{1} \%$ & $-0.17(-0.57,0.23)$ & 0 (referent) & $-0.49(-1.28,0.29)$ & $-0.53(-1.32,0.27)$ & $-0.57(-1.37,0.23)$ & 0.1791 \\
\hline \multirow[t]{4}{*}{$\Sigma \mathrm{HMW} \mathrm{OH}-\mathrm{PAH}$} & & & $<1.99$ & $1.99-3.21$ & $3.21-5.41$ & $\geq 5.41$ & \\
\hline & $\mathrm{FEV}_{1}$ & $-20.76(-37.69,-3.83)$ & 0 (referent) & $-25.06(-61.93,11.81)$ & $-31.01(-68.126 .11)$ & $-54.55(-91.82,-17.28)$ & 0.0049 \\
\hline & FVC & $-21.59(-42.18,-1.00)$ & 0 (referent) & $-9.94(-54.77,34.89)$ & $-31.06(-76.20,14.08)$ & $-54.59(-99.91,-9.27)$ & 0.0116 \\
\hline & $\mathrm{FEV}_{1} \%$ & $-0.07(-0.43,0.29)$ & 0 (referent) & $-0.58(-1.36,0.19)$ & $-0.36(-1.15,0.42)$ & $-0.30(-1.08,0.49)$ & 0.5963 \\
\hline \multirow{4}{*}{$\begin{array}{l}\sum \mathrm{LMW} \text { OH- } \\
\text { PAHs }\end{array}$} & & & $<21.68$ & $21.68-32.24$ & $32.24-49.23$ & $\geq 49.23$ & \\
\hline & $\mathrm{FEV}_{1}$ & $-19.85(-38.44,-1.26)$ & 0 (referent) & $-39.60(-76.90,-12.31)$ & $-15.47(-53.18,22.24)$ & $-61.75(-99.81,-23.70)$ & 0.0090 \\
\hline & FVC & $-16.34(-38.60,6.27)$ & 0 (referent) & $-37.59(-83.01,7.82)$ & $-3.39(-49.34,42.56)$ & $-50.65(-97.01,-4.30)$ & 0.1166 \\
\hline & $\mathrm{FEV}_{1} \%$ & $-0.19(-0.59,0.20)$ & 0 (referent) & $-0.36(-1.15,0.43)$ & $-0.42(-1.22,0.38)$ & $-0.65(-1.46,0.15)$ & 0.1205 \\
\hline
\end{tabular}

Model adjusted for age (continuous variable), gender (male/female), height (continuous variable), weight (continuous variable), smoking amounts (continuous variable), passive smoking status (yes/no), drinking status (yes/no), education level (categorical variable), annual family income (categorical variable), regular physical activity (yes/no), cooking meals at home (yes/no), sleep duration at night (continuous variable), eating smoked food $(<1 / \geq 1$ time/week), eating vegetables or fruits $(<1 / \geq 1$ time/day), eating aquatic products $(<1 / \geq 1$ time/day) and city (Wuhan/Zhuhai)

Abbreviations: $\Sigma H M W$ OH-PAH Sum of urinary high-molecular-weight monohydroxy polycyclic aromatic hydrocarbon, including 1-hydroxypyrene, $\Sigma L M W$ OH-PAHs Sum of urinary low-molecular-weight monohydroxy polycyclic aromatic hydrocarbon, including 1-hydroxynaphthalene, 2-hydroxynaphthalene, 2-hydroxyfluorene, 9-hydroxyfluorene, 1-hydroxyphenanthrene, 2-hydroxyphenanthrene, 3-hydroxyphenanthrene, 4-hydroxyphenanthrene and 9-hydroxyphenanthrene, $\Sigma O H-P A H s$

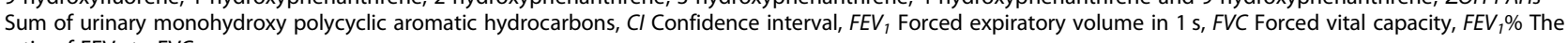
ratio of $\mathrm{FEV}_{1}$ to FVC

${ }^{a} P$ trend values of the quartile coefficients were estimated by including the original log-transformed OH-PAHs as a continuous variable

have investigated the associations between oxidative damage and lung function. Several studies have reported that oxidative stress is inversely correlated with lung function parameters in COPD patients compared with healthy controls in the USA [41], Japan [42] and China [43]. However, a cross-sectional study from Australia showed that urinary 8-OHdG of quartz-exposed workers was positively correlated with $\mathrm{FEV}_{1}$ and FVC in the case of silicosis [44]. The discrepancy may be partly explained by the different types of lung diseases and the process of DNA damage and repair status. Regarding general populations, only one adolescent study from Italy showed that urinary 8-iso-PGF2 $\alpha$ was negatively correlated with the respiratory flux index, including $\mathrm{FEF}_{50}, \mathrm{FEF}_{25-75}$ and $\mathrm{FEV}_{1} \%$ [45]. Partly consistent with previous studies, we found that an increased level of 8-OHdG was associated with decreased lung function in a general population after excluding those with diagnosed lung disease; however, we found no significant relationships between urinary 8-iso-PGF2 $\alpha$ and lung function parameters.

As an important lung function parameter, FVC can help determine both the presence and severity of restrictive airway diseases. Airway epithelial cells directly play as a natural barrier to prevent inhaled xenobiotics or particulate matter [46]. Sustained exposure to ROS could induce DNA damage in epithelial cells, triggering apoptotic pathways through the upregulation of $p 53$ and transforming growth factor $\beta$ (TGF- $\beta$ ), and secretion of multiple factors from fibroblasts [47]. Increased apoptosis of pulmonary epithelial cells may cause the loss of balance in cell turnover, and the factors induced by fibroblasts contribute to the abnormal reepithelialization. Both processes are involved in the generation of fibrosis, leading to lung compliance decline and restrictive lung function impairment [48]. Moreover, enhanced oxidative stress has been found in lung epithelial cells of patients with idiopathic interstitial pneumonia, a condition that induce DNA damage and apoptosis [49].

Although both $\Sigma \mathrm{HMW} \mathrm{OH}-\mathrm{PAH}$ and $\Sigma \mathrm{LMW} \mathrm{OH}-$ PAHs were found to be associated with oxidative damage and lung function parameters, our results indicated that the pathological effects of different molecular weight PAH exposures on lung injury might be different. It is well-known that low-molecular-weight PAHs are low in toxicity and noncarcinogenic; while highmolecular-weight PAHs, such as pyrene, the parent $\mathrm{PAH}$ of 1-OHP, demonstrate high toxic, carcinogenic and mutagenic activities [2]. In the present study, we found that urinary $8-\mathrm{OHdG}$ significantly mediated the associations between high-molecular-weight PAH metabolites and FVC. Such a mediating role of 8-OHdG was not found in the association between lowmolecular-weight PAH metabolites and lung function parameters. Relatively high oxidative DNA damage induced by high-molecular-weight $\mathrm{PAH}$ may contribute to this effect.

Our study has several strengths. First, the present study was conducted using a relatively large study 


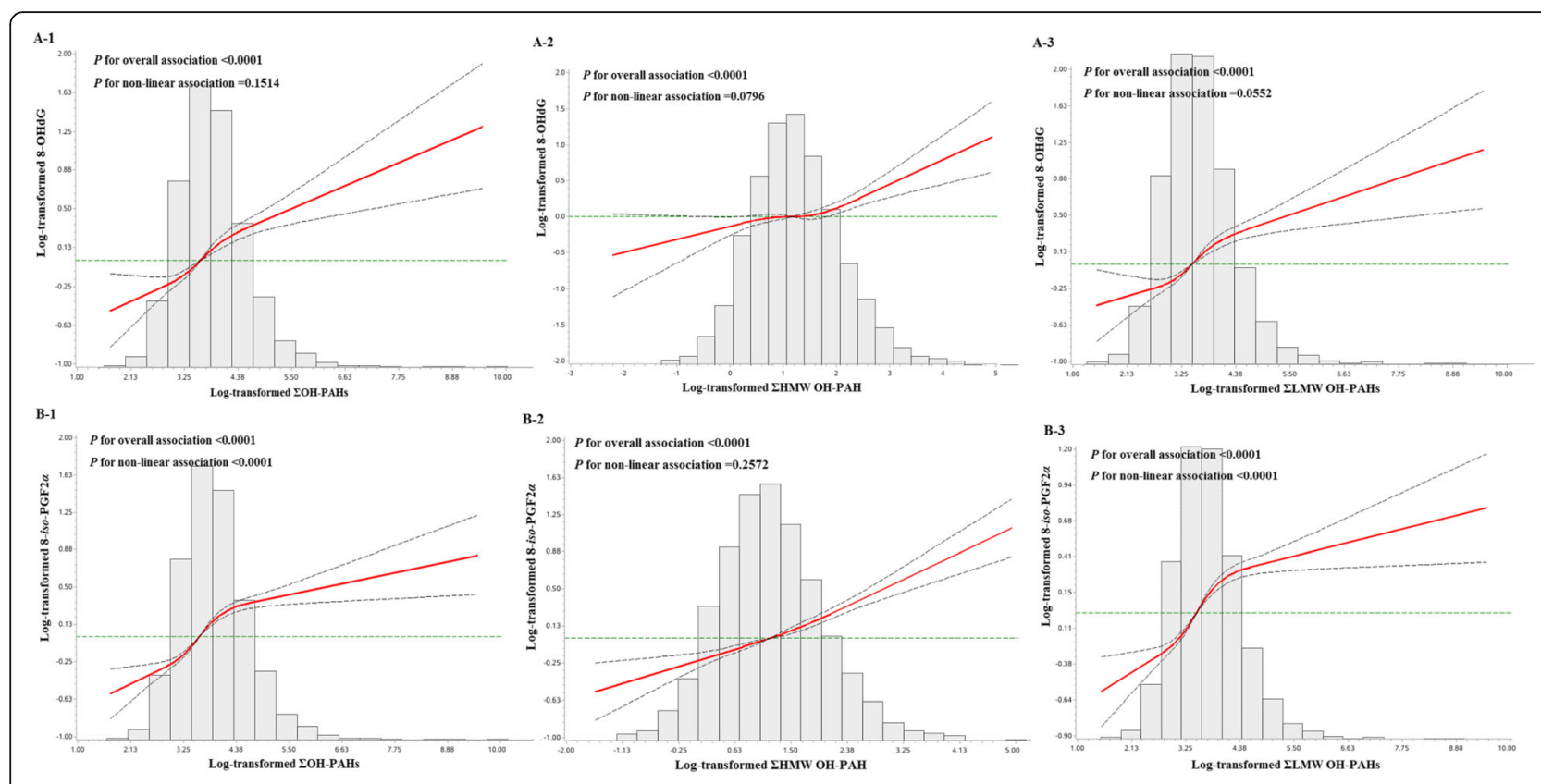

Fig. 1 Restricted cubic splines representing the associations of urinary OH-PAHs with 8-OHdG (a) and 8-iso-PGF2a (b), with adjustment for age (continuous variable), gender (male/female), height (continuous variable), weight (continuous variable), smoking amounts (continuous variable), passive smoking status (yes/no), drinking status (yes/no), education level (categorical variable), annual family income (categorical variable), regular physical activity (yes/no), cooking meals at home (yes/no), sleep duration at night (continuous variable), eating smoked food $(<1 / \geq 1$ time/week), eating vegetables or fruits $(<1 / \geq 1$ time/day), eating aquatic products $(<1 / \geq 1$ time/day) and city (Wuhan/Zhuhai). Knots were placed at the 5th, 35th, 65th 95th percentiles of the independent variables distributions, and the reference value was set at the 5th percentile. Abbreviations: $\Sigma \mathrm{HMW} \mathrm{OH}-\mathrm{PAH}$, sum of urinary high-molecular-weight monohydroxy polycyclic aromatic hydrocarbon, including 1-hydroxypyrene; $\Sigma \mathrm{LMW} \mathrm{OH}-$ PAHs, sum of urinary low-molecular-weight monohydroxy polycyclic aromatic hydrocarbon, including 1-hydroxynaphthalene, 2-

hydroxynaphthalene, 2-hydroxyfluorene, 9-hydroxyfluorene, 1-hydroxyphenanthrene, 2-hydroxyphenanthrene, 3-hydroxyphenanthrene, 4hydroxyphenanthrene and 9-hydroxyphenanthrene; $\Sigma \mathrm{OH}-\mathrm{PAHs}$, sum of urinary monohydroxy polycyclic aromatic hydrocarbons; 8-iso-PGF2a, 8isoprostane; 8-OHdG, 8-hydroxy-2'-deoxyguanosine; $\mathrm{OH}-\mathrm{PAHs}$, urinary monohydroxy polycyclic aromatic hydrocarbons

population of 3367 participants. Second, we measured 10 types of urinary OH-PAHs, which could reflect internal PAH exposure levels from all potential sources. Additionally, choosing urinary $8-\mathrm{OHdG}$ and 8-isoPGF $2 \alpha$ to represent systemic oxidative damage levels is a more comprehensive approach that, may provide a clue to help interpret the potential mechanism. One limitation in our study is that determining the levels of $\mathrm{OH}$ $\mathrm{PAH}$ in a single spot urine sample might not reflect the long-term exposure levels of PAHs, although the life

Table 3 Associations between oxidative damage and lung function parameters $(N=3367)$

\begin{tabular}{|c|c|c|c|c|c|c|c|}
\hline \multirow{2}{*}{$\begin{array}{l}\text { Oxidative } \\
\text { damage }\end{array}$} & \multirow{2}{*}{$\begin{array}{l}\text { Lung } \\
\text { function } \\
\text { parameters }\end{array}$} & \multirow{2}{*}{$\begin{array}{l}\text { Estimated changes } \\
(95 \% \mathrm{Cl}) \text { by } \\
\text { continuous } \\
\text { OH-PAHs }\end{array}$} & \multicolumn{4}{|c|}{ Estimated changes in $\mathrm{ml}(95 \% \mathrm{Cl})$ by quartile of oxidative damage } & \multirow{2}{*}{$\begin{array}{l}P \text { value } \\
\text { for trend }\end{array}$} \\
\hline & & & Quartile 1 & Quartile 2 & Quartile 3 & Quartile 4 & \\
\hline \multirow[t]{3}{*}{$8-\mathrm{OHdG}$} & & & $<28.79$ & $28.79-63.18$ & $63.18-125.04$ & $\geq 125.04$ & \\
\hline & $\mathrm{FEV}_{1}$ & $-6.08(-17.28,5.11)$ & 0 (referent) & $-8.51(-45.57,28.55)$ & $-10.00(-47.14,27.15)$ & $-21.92(-59.30,15.45)$ & 0.2651 \\
\hline & FVC & $-17.48(-31.08,-3.88)$ & 0 (referent) & $-16.98(-62.01,28.06)$ & $-17.65(-62.79,27.49)$ & $-46.03(-90.65,-1.41)$ & 0.0430 \\
\hline \multirow[t]{3}{*}{ 8-iso-PGF2a } & & & $<109.09$ & 109.09-176.89 & $176.89-310.79$ & $\geq 310.79$ & \\
\hline & $\mathrm{FEV}_{1}$ & $-11.31(-29.56,6.93)$ & 0 (referent) & $3.25(-32.62,39.13)$ & $-8.71(-44.37,26.96)$ & $-13.57(-50.12,22.98)$ & 0.4241 \\
\hline & FVC & $-16.15(-38.38,6.07)$ & 0 (referent) & $3.57(-40.06,47.20)$ & $-19.90(-63.26,23.45)$ & $-26.93(-71.51,17.65)$ & 0.1813 \\
\hline
\end{tabular}

Model adjusted for age (continuous variable), gender (male/female), height (continuous variable), weight (continuous variable), smoking amounts (continuous variable), passive smoking status (yes/no), drinking status (yes/no), education level (categorical variable), annual family income (categorical variable), regular physical activity (yes/no), cooking meals at home (yes/no), sleep duration at night (continuous variable), eating smoked food $(<1 / \geq 1$ time/week), eating vegetables or fruits $(<1 / \geq 1$ time/day), eating aquatic products $(<1 / \geq 1$ time/day) and city (Wuhan/Zhuhai) Abbreviations: 8-iso-PGF2a 8-isoprostane, 8-OHdG 8-hydroxy-2'-deoxyguanosine, Cl Confidence interval, FEV 1 Forced expiratory volume in $1 \mathrm{~s}$, FVC Forced vital capacity

${ }^{a} P$ trend values of the quartile coefficients were estimated by including the original log-transformed oxidative damage as a continuous variable 
Table 4 Total and direct effect of urinary OH-PAHs on lung function alteration and assessment of 8-OHdG $(\mathrm{N}=3367)$

\begin{tabular}{|c|c|c|c|c|}
\hline & Total effects ${ }^{a}$ & Direct effects $^{b}$ & $\begin{array}{l}\text { Mediated effect of } \\
8-\mathrm{OHdG}^{c}\end{array}$ & Proportion mediated (\%) \\
\hline \multicolumn{5}{|l|}{$\mathrm{FEV}_{1}$} \\
\hline$\Sigma \mathrm{OH}-\mathrm{PAHS}$ & $-21.76(-40.74,-2.79)$ & $-20.52(-39.80,-1.25)$ & $-1.24(-4.78,2.74)$ & $N A^{d}$ \\
\hline$\Sigma \mathrm{HMW} O \mathrm{OH}-\mathrm{PAH}$ & $-20.49(-37.44,-3.53)$ & $-19.61(-36.69,-2.52)$ & $-0.88(-3.22,1.48)$ & $N A^{d}$ \\
\hline$\Sigma \mathrm{LMW}$ OH-PAHS & $-20.19(-38.81,-1.57)$ & $-18.93(-37.85,-0.02)$ & $-1.26(-5.07,2.15)$ & $N A^{d}$ \\
\hline \multicolumn{5}{|l|}{ FVC } \\
\hline$\Sigma \mathrm{OH}-\mathrm{PAHS}$ & $-18.93(-42.02,4.16)$ & $-14.10(-37.54,9.34)$ & $-4.83(-9.89,-0.45)$ & $N A^{d}$ \\
\hline$\Sigma \mathrm{HMW} O \mathrm{OH}-\mathrm{PAH}$ & $-21.33(-41.96,-0.71)$ & $-18.30(-39.07,2.47)$ & $-3.03(-6.23,-0.57)$ & $14.22 \%$ \\
\hline$\Sigma \mathrm{LMW} \mathrm{OH}-\mathrm{PAHS}$ & $-16.46(-39.12,6.20)$ & $-11.66(-34.66,11.35)$ & $-4.80(-9.62,-0.66)$ & $N A^{d}$ \\
\hline
\end{tabular}

Covariates in the SPSS commands include age (continuous variable), gender (male/female), height (continuous variable), weight (continuous variable), smoking amounts (continuous variable), passive smoking status (yes/no), drinking status (yes/no), education level (categorical variable), annual family income (categorical variable), regular physical activity (yes/no), cooking meals at home (yes/no), sleep duration at night (continuous variable), eating smoked food ( $<1 / \geq 1$ time/week), eating vegetables or fruits $(<1 / \geq 1$ time/day), eating aquatic products $(<1 / \geq 1$ time/day) and city (Wuhan/Zhuhai)

Abbreviations: $\Sigma H M W$ OH-PAH Sum of urinary high-molecular-weight monohydroxy polycyclic aromatic hydrocarbon, including 1 -hydroxypyrene, $\Sigma L M W$ OH-PAHs Sum of urinary low-molecular-weight monohydroxy polycyclic aromatic hydrocarbon, including 1-hydroxynaphthalene, 2-hydroxynaphthalene, 2-hydroxyfluorene, 9-hydroxyfluorene, 1-hydroxyphenanthrene, 2-hydroxyphenanthrene, 3-hydroxyphenanthrene, 4-hydroxyphenanthrene and 9-hydroxyphenanthrene, $\Sigma \mathrm{OH}-\mathrm{PAHS}$

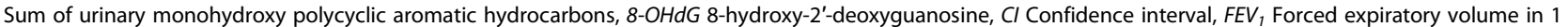
s, FVC Forced vital capacity

${ }^{a}$ Total effects of urinary OH-PAHs on lung function parameters were estimated without adjusting for urinary $8-\mathrm{OHdG}$

${ }^{b}$ Direct effects of urinary $\mathrm{OH}-\mathrm{PAH}$ s on lung function parameters were estimated with adjusting for urinary 8-OHdG

'The mediated effect of 8-OHdG was obtained from the model, which simultaneously included OH-PAHs, 8-OHdG, lung function parameters and covariates by performing in the PROCESS SPSS macro

dProportion mediated by $8-\mathrm{OHdG}$ cannot be tested because of the opposite signs between total effect and indirect effect

habits (including dietary pattern, travel mode, smoking status and other potential exposure routes for PAHs) of the study population were relatively stable. Further prospective studies are warranted. Furthermore, except for PAHs, exposure to other unmeasured toxic substances in the environment may also cause lung damage. Thus, the synergistic effects of multiple pollutants should be considered in further research. In addition, because 8OHdG is a nonspecific biomarker for oxidative stress in lung tissue, to clarify the etiological pathway, it is necessary to identify more specific biomarkers.

\section{Conclusion}

Urinary OH-PAHs levels were negatively associated with lung function, but positively related to the levels of oxidative stress. Moreover, our findings suggest that urinary 8-OHdG may play an important role in the association between high-molecular-weight PAH exposure and FVC, further providing a clue to the potential underlying mechanism of lung damage related to PAH exposure. More studies are needed to identify specific biomarkers to elucidate this damage process.

\section{Abbreviations}

$\Sigma$ HMW OH-PAH: Sum of high-molecular-weight monohydroxy polycyclic aromatic hydrocarbon; $\Sigma$ LMW OH-PAHs: Sum of low-molecular-weight monohydroxy polycyclic aromatic hydrocarbons; $\Sigma \mathrm{OH}-\mathrm{PAH}$ : Sum of urinary monohydroxy polycyclic aromatic hydrocarbons; 1-OHNa: 1hydroxynaphthalene; 1-OHP: 1-hydroxypyrene; 1-OHPh: 1hydroxyphenanthrene; 2-OHFlu: 2-hydroxyfluorene; 2-OHNa: 2hydronaphthalene; 2-OHPh: 2-hydroxyphenanthrene; 3-OHPh: 3- hydroxyphenanthrene; 4-OHPh: 4-hydroxyphenanthrene; 8-iso-PGF2a: 8isoprostane; 8-OHdG: 8-hydroxy-2'-deoxyguanosine; 9-OHFlu: 9hydroxyfluorene; 9-OHPh: 9-hydroxyphenanthrene; BMI: Body mass index; $\mathrm{Cl}$ : Confidence interval; creat.: Creatinine; $\mathrm{FEV}_{1}$ : Forced expiratory volume in 1 s; FVC: Forced vital capacity; FEV $\%$ : The ratio of FEV 1 to FVC; GC-MS: Gas chromatography-mass spectrometry; HPLC: High-performance liquid chromatography; IQR: Interquartile range; LOD: The limits of detection; $\mathrm{OH}$ PAHs: Monohydroxy polycyclic aromatic hydrocarbons metabolites; PAHs: Polycyclic aromatic hydrocarbons; SD: Standard deviation

\section{Acknowledgments}

We thank all the participants involved in the study.

\section{Authors' contributions}

WC was responsible for the design of the Wuhan-Zhuhai cohort study, funding obtaining, reviewed the manuscript, and assisted with manuscript revision. LC organized the study in the field, conducted data collection and abstraction, performed data analyses, measured and quantified urinary creatinine, $\mathrm{OH}-\mathrm{PAHs}$ and 8-iso-PGF2a levels, drafted and revised the manuscript. YZ supervised or conducted data collection and abstraction, reviewed the analysis and the manuscript. AT and TS supervised data collection and abstraction, coordinated study personnel, reviewed the manuscript and assisted with manuscript revision. CZ and LX coordinated the data collection, measured and quantified urinary $8-\mathrm{OHdG}$ levels, and reviewed the manuscript. ZZ, SY, GM and XW coordinated the data collection, measured and quantified urinary creatinine, $\mathrm{OH}-\mathrm{PAH}$ s and 8-iso-PGF2a levels, and reviewed the manuscript. DW and JM supervised or conducted data collection and abstraction, funding obtaining, reviewed the manuscript, and assisted with manuscript revision. All authors read and approved the final manuscript.

\section{Funding}

This work was supported by the Major Research Program of the National Natural Science Foundation of China [grant number 91843302], the Key Program of the National Natural Science Foundation of China [grant number 91543207], and the China Postdoctoral Science Foundation funded project [grant number 2019 T120666, 2018 M640705]. 


\section{Availability of data and materials}

The datasets generated and analyzed during the present study are not publicly available due to privacy concerns, as they contain sensitive and protected health data on participants. Specific requests to access the data can be sent to wchen@mails.tjmu.edu.cn.

\section{Ethics approval and consent to participate}

All participants in the present study signed written informed consent. The research protocol was approved by the Ethics and Human Subjects Committee of Tongji Medical College, Huazhong University of Science and Technology, P. R. China.

\section{Consent for publication}

Not applicable.

\section{Competing interests}

The authors declare that they have no competing interests.

\section{Author details}

'Department of Occupational \& Environmental Health, School of Public Health, Tongji Medical College, Huazhong University of Science and Technology, Wuhan 430030, Hubei, China. ${ }^{2}$ Key Laboratory of Environment and Health, Ministry of Education \& Ministry of Environmental Protection, and State Key Laboratory of Environmental Health (Incubating), School of Public Health, Tongji Medical College, Huazhong University of Science and Technology, Wuhan 430030, Hubei, China. ${ }^{3}$ Zhuhai Center for Disease Control and Prevention, Zhuhai 519000, Guangdong, China. ${ }^{4}$ Hubei Center for Disease Control and Prevention, Wuhan 430079, Hubei, China.

Received: 25 July 2019 Accepted: 8 June 2020

Published online: 02 July 2020

\section{References}

1. Wang L, Li C, Jiao B, Li Q, Su H, Wang J, Jin F. Halogenated and parent polycyclic aromatic hydrocarbons in vegetables: levels, dietary intakes, and health risk assessments. Sci Total Environ. 2018;616-617:288-95.

2. Kim KH, Jahan SA, Kabir E, Brown RJ. A review of airborne polycyclic aromatic hydrocarbons (PAHs) and their human health effects. Environ Int. 2013;60:71-80

3. Hu C, Hou J, Zhou Y, Sun H, Yin W, Zhang Y, Wang X, Wang G, Chen W, Yuan J. Association of polycyclic aromatic hydrocarbons exposure with atherosclerotic cardiovascular disease risk: a role of mean platelet volume or club cell secretory protein. Environ Pollut. 2018;233:45-53.

4. $\quad$ Yang P, Wang YX, Chen YJ, Sun L, Li J, Liu C, Huang Z, Lu WQ, Zeng Q. Urinary polycyclic aromatic hydrocarbon metabolites and human semen quality in China. Environ Sci Technol. 2017;51(2):958-67.

5. Ma J, Zhou Y, Liu Y, Xiao L, Cen X, Li W, Guo Y, Kim M, Yuan J, Chen W. Association between urinary polycyclic aromatic hydrocarbon metabolites and dyslipidemias in the Chinese general population: a cross-sectional study. Environ Pollut. 2019;245:89-97.

6. Lee DG, Burstyn I, Lai AS, Grundy A, Friesen MC, Aronson KJ, Spinelli JJ. Women's occupational exposure to polycyclic aromatic hydrocarbons and risk of breast cancer. Occup Environ Med. 2019;76(1):22-9.

7. Yang L, Zhou Y, Sun H, Lai H, Liu C, Yan K, Yuan J, Wu T, Chen W, Zhang X. Dose-response relationship between polycyclic aromatic hydrocarbon metabolites and risk of diabetes in the general Chinese population. Environ Pollut. 2014;195:24-30.

8. Zhou Y, Sun H, Xie J, Song Y, Liu Y, Huang X, Zhou T, Rong Y, Wu T, Yuan J, et al. Urinary polycyclic aromatic hydrocarbon metabolites and altered lung function in Wuhan, China. Am J Respir Crit Care Med. 2016;193(8):835-46.

9. Petit P, Maitre A, Persoons R, Bicout DJ. Lung cancer risk assessment for workers exposed to polycyclic aromatic hydrocarbons in various industries. Environ Int. 2019;124:109-20.

10. Schunemann HJ, Dorn J, Grant BJ, Winkelstein W Jr, Trevisan M. Pulmonary function is a long-term predictor of mortality in the general population: 29year follow-up of the Buffalo health study. Chest. 2000;118(3):656-64.

11. Stavem K, Aaser E, Sandvik L, Bjornholt JV, Erikssen G, Thaulow E, Erikssen J. Lung function, smoking and mortality in a 26-year follow-up of healthy middle-aged males. Eur Respir J. 2005;25(4):618-25.
12. Hong YC, Park EY, Park MS, Ko JA, Oh SY, Kim H, Lee KH, Leem JH, Ha EH. Community level exposure to chemicals and oxidative stress in adult population. Toxicol Lett. 2009;184(2):139-44.

13. Ichinose T, Yajima Y, Nagashima M, Takenoshita S, Nagamachi Y, Sagai M. Lung carcinogenesis and formation of 8-hydroxy-deoxyguanosine in mice by diesel exhaust particles. Carcinogenesis. 1997;18(1):185-92

14. Vattanasit U, Navasumrit P, Khadka MB, Kanitwithayanun J, Promvijit J, Autrup $\mathrm{H}$, Ruchirawat M. Oxidative DNA damage and inflammatory responses in cultured human cells and in humans exposed to traffic-related particles. Int J Hyg Environ Health. 2014;217(1):23-33.

15. Palackal NT, Lee SH, Harvey RG, Blair IA, Penning TM. Activation of polycyclic aromatic hydrocarbon trans-dihydrodiol proximate carcinogens by human aldo-keto reductase (AKR1C) enzymes and their functional overexpression in human lung carcinoma (A549) cells. J Biol Chem. 2002;277(27):24799-808.

16. Valavanidis A, Vlachogianni T, Fiotakis C. 8-hydroxy-2' -deoxyguanosine (8$\mathrm{OHdG}$ ): a critical biomarker of oxidative stress and carcinogenesis. J Environ Sci Health C Environ Carcinog Ecotoxicol Rev. 2009;27(2):120-39.

17. Hu C, Wang G, Yin W, Zhou Y, Hou J, Wang X, Chen W, Yuan J. Central obesity transition increased urinary levels of 8-hydroxydeoxyguanosine in male adults: a 3-year follow up study. Metabolism. 2019;91:53-60.

18. Kuang D, Zhang W, Deng Q, Zhang X, Huang K, Guan L, Hu D, Wu T, Guo $H$. Dose-response relationships of polycyclic aromatic hydrocarbons exposure and oxidative damage to DNA and lipid in coke oven workers. Environ Sci Technol. 2013;47(13):7446-56.

19. Cracowski JL, Durand T, Bessard G. Isoprostanes as a biomarker of lipid peroxidation in humans: physiology, pharmacology and clinical implications. Trends Pharmacol Sci. 2002;23(8):360-6.

20. Ferguson KK, McElrath TF, Pace GG, Weller D, Zeng L, Pennathur S, Cantonwine DE, Meeker JD. Urinary polycyclic aromatic hydrocarbon metabolite associations with biomarkers of inflammation, angiogenesis, and oxidative stress in pregnant women. Environ Sci Technol. 2017;51(8): 4652-60.

21. Wang Y, Lin J, Shu J, Li H, Ren Z. Oxidative damage and DNA damage in lungs of an ovalbumin-induced asthmatic murine model. J Thorac Dis. 2018; 10(8):4819-30.

22. MacNee W. Oxidative stress and lung inflammation in airways disease. Eur J Pharmacol. 2001:429(1-3):195-207.

23. Bartoli ML, Novelli F, Costa F, Malagrino L, Melosini L, Bacci E, Cianchetti S, Dente FL, Di Franco A, Vagaggini B, et al. Malondialdehyde in exhaled breath condensate as a marker of oxidative stress in different pulmonary diseases. Mediat Inflamm. 2011:2011:891752.

24. Kazmierczak M, Ciebiada M, Pekala-Wojciechowska A, Pawlowski M, Nielepkowicz-Gozdzinska A, Antczak A. Evaluation of markers of inflammation and oxidative stress in COPD patients with or without cardiovascular comorbidities. Heart Lung Circ. 2015;24(8):817-23.

25. Maluf SW, Mergener M, Dalcanale L, Costa CC, Pollo T, Kayser M, da Silva LB, Pra D, Teixeira PJ. DNA damage in peripheral blood of patients with chronic obstructive pulmonary disease (COPD). Mutat Res. 2007:626(1-2):180-4.

26. Gerritsen WB, Asin J, Zanen P, van den Bosch JM, Haas FJ. Markers of inflammation and oxidative stress in exacerbated chronic obstructive pulmonary disease patients. Respir Med. 2005;99(1):84-90.

27. Psathakis K, Mermigkis D, Papatheodorou G, Loukides S, Panagou P, Polychronopoulos V, Siafakas NM, Bouros D. Exhaled markers of oxidative stress in idiopathic pulmonary fibrosis. Eur J Clin Investig. 2006;36(5):362-7.

28. Shimizu Y, Dobashi K, Sano T, Yamada M. ROCK activation in lung of idiopathic pulmonary fibrosis with oxidative stress. Int J Immunopathol Pharmacol. 2014;27(1):37-44

29. Song $Y$, Hou J, Huang $X$, Zhang $X$, Tan A, Rong $Y$, Sun H, Zhou Y, Cui X, Yang $Y$, et al. The Wuhan-Zhuhai $(W H Z H)$ cohort study of environmental air particulate matter and the pathogenesis of cardiopulmonary diseases: study design, methods and baseline characteristics of the cohort. BMC Public Health. 2014;14:994.

30. Li X, Feng Y, Deng H, Zhang W, Kuang D, Deng Q, Dai X, Lin D, Huang S, Xin $L$, et al. The dose-response decrease in heart rate variability: any association with the metabolites of polycyclic aromatic hydrocarbons in coke oven workers? PLoS One. 2012;7(9):e44562.

31. Sun H, Hou J, Zhou Y, Yang Y, Cheng J, Xu T, Xiao L, Chen W, Yuan J. Doseresponse relationship between urinary polycyclic aromatic hydrocarbons metabolites and urinary 8-hydroxy-2'-deoxyguanosine in a Chinese general population. Chemosphere. 2017;174:506-14. 
32. Preacher KJ, Hayes AF. Asymptotic and resampling strategies for assessing and comparing indirect effects in multiple mediator models. Behav Res Methods. 2008;40(3):879-91.

33. Shen $M$, Xing J, Ji Q, Li Z, Wang Y, Zhao H, Wang Q, Wang T, Yu L, Zhang X, et al. Declining pulmonary function in populations with long-term exposure to polycyclic aromatic hydrocarbons-enriched PM2.5. Environ Sci Technol. 2018;52(11):6610-6.

34. Majewska R, Pac A, Mroz E, Spengler J, Camann D, Mrozek-Budzyn D, Sowa A, Jacek R, Wheelock K, Perera FP. Lung function growth trajectories in nonasthmatic children aged 4-9 in relation to prenatal exposure to airborne particulate matter and polycyclic aromatic hydrocarbons - Krakow birth cohort study. Environ Res. 2018;166:150-7.

35. Padula AM, Balmes JR, Eisen EA, Mann J, Noth EM, Lurmann FW, Pratt B, Tager IB, Nadeau K, Hammond SK. Ambient polycyclic aromatic hydrocarbons and pulmonary function in children. J Expo Sci Environ Epidemiol. 2015;25(3):295-302.

36. Cakmak S, Hebbern C, Cakmak JD, Dales RE. The influence of polycyclic aromatic hydrocarbons on lung function in a representative sample of the Canadian population. Environ Pollut. 2017;228:1-7.

37. Kho Y, Lee EH, Chae HJ, Choi K, Paek D, Park S. 1-Hydroxypyrene and oxidative stress marker levels among painting workers and office workers at shipyard. Int Arch Occup Environ Health. 2015;88(3):297-303.

38. van der Vaart H, Postma DS, Timens W, ten Hacken NH. Acute effects of cigarette smoke on inflammation and oxidative stress: a review. Thorax. 2004;59(8):713-21.

39. van 't Erve TJ, Lih FB, Kadiiska MB, Deterding L, Mason RP. Elevated plasma 8-iso-prostaglandin F2alpha levels in human smokers originate primarily from enzymatic instead of non-enzymatic lipid peroxidation. Free Radic Biol Med. 2018;115:105-12.

40. Klaunig JE, Kamendulis LM. The role of oxidative stress in carcinogenesis. Annu Rev Pharmacol Toxicol. 2004;44:239-67.

41. Kinnula VL, llumets H, Myllarniemi M, Sovijarvi A, Rytila P. 8-Isoprostane as a marker of oxidative stress in nonsymptomatic cigarette smokers and COPD. Eur Respir J. 2007;29(1):51-5.

42. Igishi T, Hitsuda Y, Kato K, Sako T, Burioka N, Yasuda K, Sano H, Shigeoka Y, Nakanishi H, Shimizu E. Elevated urinary 8-hydroxydeoxyguanosine, a biomarker of oxidative stress, and lack of association with antioxidant vitamins in chronic obstructive pulmonary disease. Respirology. 2003;8(4): 455-60.

43. Liu X, Deng K, Chen S, Zhang Y, Yao J, Weng X, Zhang Y, Gao T, Feng G. 8Hydroxy-2'-deoxyguanosine as a biomarker of oxidative stress in acute exacerbation of chronic obstructive pulmonary disease. Turk J Med Sci. 2019;49(1):93-100.

44. Pilger A, Germadnik D, Schaffer A, Theiler A, Pils P, Sluka F, Winker N, Rudiger HW. 8-Hydroxydeoxyguanosine in leukocyte DNA and urine of quartz-exposed workers and patients with silicosis. Int Arch Occup Environ Health. 2000;73(5):305-10.

45. Bono R, Tassinari R, Bellisario V, Gilli G, Pazzi M, Pirro V, Mengozzi G, Bugiani M, Piccioni P. Urban air and tobacco smoke as conditions that increase the risk of oxidative stress and respiratory response in youth. Environ Res. 2015; 137:141-6.

46. Gao W, Li L, Wang Y, Zhang S, Adcock IM, Barnes PJ, Huang M, Yao X. Bronchial epithelial cells: the key effector cells in the pathogenesis of chronic obstructive pulmonary disease? Respirology. 2015;20(5):722-9.

47. Plataki M, Koutsopoulos AV, Darivianaki K, Delides G, Siafakas NM, Bouros D. Expression of apoptotic and antiapoptotic markers in epithelial cells in idiopathic pulmonary fibrosis. Chest. 2005;127(1):266-74.

48. Gutteridge JM, Halliwell B. Free radicals and antioxidants in the year 2000. A historical look to the future. Ann N Y Acad Sci. 2000:899:136-47.

49. Kuwano K, Nakashima N, Inoshima I, Hagimoto N, Fujita M, Yoshimi M, Maeyama T, Hamada N, Watanabe K, Hara N. Oxidative stress in lung epithelial cells from patients with idiopathic interstitial pneumonias. Eur Respir J. 2003;21(2):232-40.

\section{Publisher's Note}

Springer Nature remains neutral with regard to jurisdictional claims in published maps and institutional affiliations.

\section{Ready to submit your research? Choose BMC and benefit from:}

- fast, convenient online submission

- thorough peer review by experienced researchers in your field

- rapid publication on acceptance

- support for research data, including large and complex data types

- gold Open Access which fosters wider collaboration and increased citations

- maximum visibility for your research: over $100 \mathrm{M}$ website views per year

At BMC, research is always in progress.

Learn more biomedcentral.com/submissions 